\title{
APLIKASI SISTEM PENDUKUNG KEPUTUSAN PEMILIHAN JURUSAN SISWA-SISWI SMA (MIPA/IPS/BAHASA) MENGGUNAKAN METODE AHP
}

\author{
Didin adianto ${ }^{1}$, Harun Sujadi ${ }^{2}$, \\ Teknik Informatika, Fakultas Teknik Universitas Majalengka \\ Email: harunsujadi@gmail.com, didinadianto@gmail.com
}

\begin{abstract}
Abstrack
SMA Negeri 1 Majalengka established on 1 August 1961. Before becoming an independent school SMA Negeri 1 Majalengka a remote class of SMA Negeri 1 Kuningan. Application development Application Decision Support System is based on manual systems that are running on the SMA Negri 1 Majalengka. The system is running here is interest still using questionnaires.

Based on the requirements made Selection Decision Support System Application Programs High School Students using Object Oriented development techniques. While the method of data flow systems using Analytical Hierarchy Process (AHP), where his tools are the Unified Modeling Language (UML) to describe the functional model is the use case diagram to illustrate the data model. Specialization process can be done with this application.

After going through the stages in accordance with the selected development method hence in implementing decision support system for the selection of this department have follow-up testing system consisting of alpha testing where this test using blackbox testing method that focuses on the functional requirements of the software. After testing it can be concluded that the Decision Support System created by using Analytic Hierarchy Process (AHP), which is expected to assist in the selection of high school majors.
\end{abstract}

Keywords $\quad$ : Decision Support System, Specialisation, Object Oriented, AHP, Use Case Diagram

\section{PENDAHULUAN}

Agar mampu berperan dalam persaingan global, maka sebagai bangsa kita perlu terus mengembangkan dan meningkatkan kualitas sumber daya manusianya. Kemajuan teknologi sudah mengalami perkembangan yang pesat, masih ada berbagai instansi pendidikan atau sekolah yang belum mengkomputerisasikan sistem penjurusan dan masih dilakukan secara manual. Hal ini menyebabkan keterlambatan dalam pembuatan laporan yang berkaitan dengan lambatnya informasi sehingga akan banyak menyita waktu dan pengolahan data terhadap kesalahan lebih besar. Oleh karena itu, berbagai instansi termasuk instansi pendidikan sangat membutuhkan alat bantu dalam mengambil keputusan.

Alat bantu tersebut adalah komputer yang salah satu fungsinya adalah pendukung dalam mengambil keputusan seorang manager tingkat atas, teknologi informasi merupakan suatu usaha pengumpulan, penyimpanan, pengolahan, penyebaran dan pemanfaatan informasi yang meliputi bidang IPTEK dan perekayasaan serta teknik-teknik pengelolaannya.

Banyak siswa kelas IX bingung untuk memilih jurusan apa yang akan mereka pilih untuk naik di kelas $X$, minat, bakat dan nilai akademik siswa pun kadangkala tidak sejalan. Guru pun belum bisa mengukur kemampuan siswa dari segi bakat dan akademik.Kadangkala guru hanya mengukur dari segi nilai rapor atau ranking di kelas.

Hal ini tentunya menyulitkan siswa untuk masuk ke jurusan sesuai dengan bakatnya.Untuk itulah peneliti melakukan penelitian tentang penjurusan SMA untuk membantu siswa dalam memilih jurusan sesuai dengan bakat dan akademik masing-masing siswa.Dengan menggunakan metode AHP (Analytical Hierarchy Process) sebagai model analisis uji komparasi dan pendekatan yang digunakan berdasarkan analisis kebijakan yang bertujuan untuk mendapatkan keputusan yang tepat dan optimal bagi guru.

Untuk mengatasi masalah-masalah tersebut,diperlukan adanya sistem yang 
terkomputerisasi yang baru untuk meningkatkan efisiensi kerja. Dengan adanya kesempatan ini,penulis mengadakan wawancara dengan kepala sekolah yang dilakukan selama ini dan dituangkan dalam bentuk penelitian. Penelitian ini difokuskan pada Aplikasi sistem pendukung keputusan pemilihan jurusan di SMAN 1 Majalengka menggunakan Metode AHP (Analytical Hierarchy Process)

\section{METODE PENELITIAN}

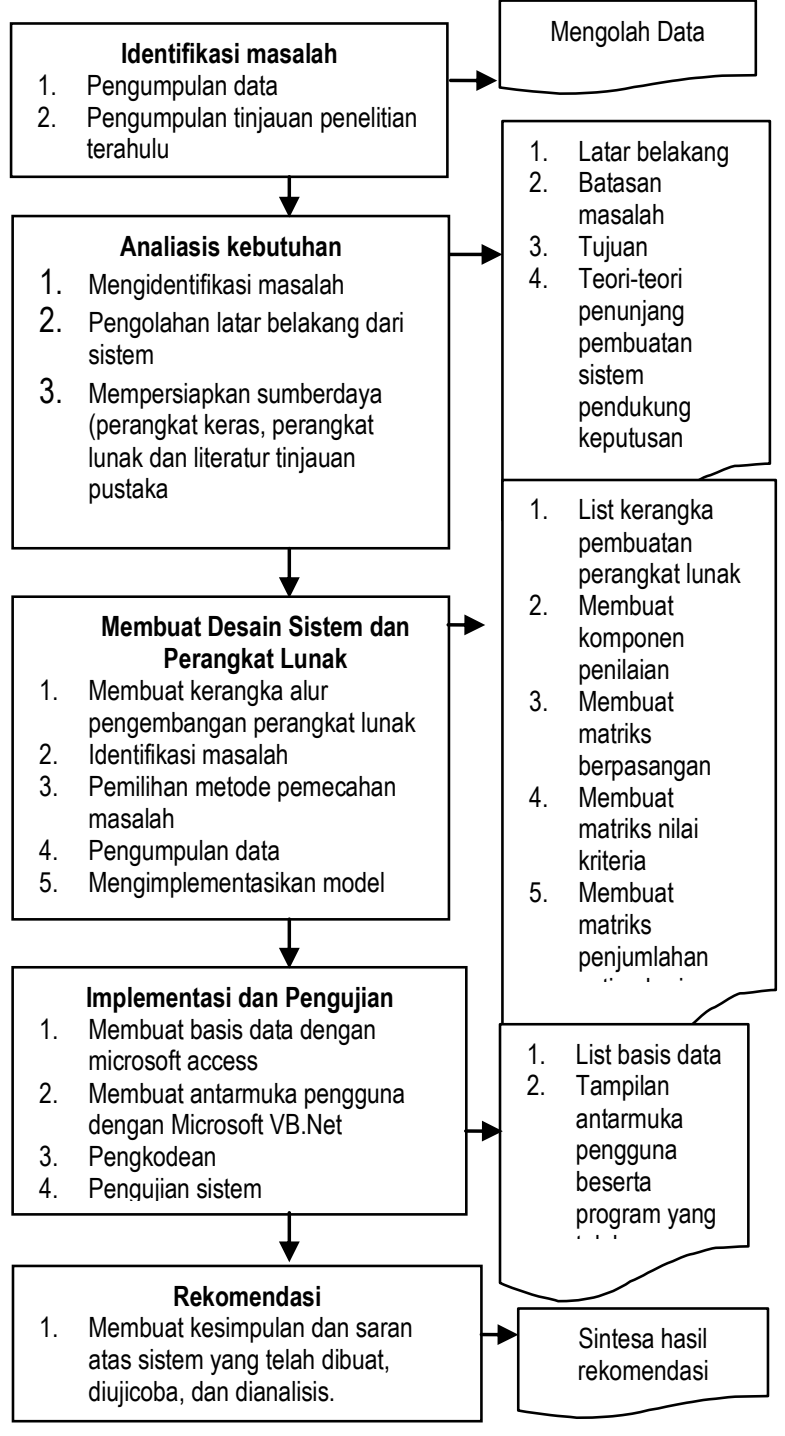

1. Identifikasi Masalah

Tahap ini adalah mengumpulkan dan mengelola data yang dibutuhkan untuk tahap selanjutny yang akan dianalisis kebutuhan

2. Analisis Kebutuhan

Tahapan ini adalah menganalisa kebutuhan-kebutuhan yang ada untuk diolah menjadi suatu sistem
3. Membuat Desain Sistem Perangkat Lunak Tahapan ini merupakan pembuatan desain program yang nantinya akan diimplementasikan

4. Implementasi dan Pengujian

Tahapan ini merupakan implementasi program yang akan di uji

5. Rekomendasi

Tahapan ini merupakan tahapan akhir untuk hasil atau bluprin

\section{HASIL DAN PEMBAHASAN}

Berdasarkan observasi dan interview dengan pihak SMAN 1 Majalengka, didapatkan kesimpulan permasalahan dalam pemilihan jurusan masih menggunakan cara manual yaitu dengan menggunakan formulir/angket, sehingga kurang epektifnya siswa dalam memilih jurusan. Berdasarkan permasalahan yang telah diuraikan maka perlu dibangunnya aplikasi yang terkomputerisasi untuk memaksimalkan dalam proses pemilihan jurusan.

Komponen penilaian untuk pemilihan jurusan di SMAN 1 Majalengka yaitu:

1. Mengambil dan menghitung rata-rata nilai perbidang jurusan $\frac{\text { nilai rata-rata }}{3} \times 100$

2. Mengambil data hasil psikotes $\frac{\text { nilai yang di peroleh }}{\text { nilai standar jurusan }} \times 100$

3. Mengikuti kuis peminatan jurusan $\frac{\text { nilai yang di peroleh }}{\text { nilai standar jurusan }} \times 100$

Proses penentuan prioritas menggunakan metode AHP dimulai dari perumusan masalah yaitu proses untuk pemilihan jurusan untuk membantu pihak sekolah memproleh hasil yang lebih akurat. Perancangan ini meliputi 2 tahap yaitu proses analisis kebutuhan perangkat lunak dan perancangan sistem pendukung keputusan menggunakan metode AHP (Analytical Hierarchy Process). Tahap analisis kebutuhan perangkat lunak terdiri dari identifikasi aktor, daftar kebutuhan sistem, dan use case diagram.Tahap perancangan sistem pendukung keputusan terdiri dari Langkah metode AHP, hasil keputusan metode AHP dan user interface. 


\section{Membuat Matriks Berpasangan}

Pada tahap ini dilakukan penilaian perbandingan antara satu kriteria dengan kriteria yang lain.Hasil penilaian bisa dilihat dalam tabel 3.1

Tabel 3.1 Matriks Perbandingan Berpasangan

\begin{tabular}{|l|c|c|c|}
\hline & $\begin{array}{c}\text { Nilai } \\
\text { rata- } \\
\text { rata }\end{array}$ & $\begin{array}{c}\text { Hasil } \\
\text { psikotes }\end{array}$ & $\begin{array}{c}\text { Hasil kuis } \\
\text { peminatan }\end{array}$ \\
\hline $\begin{array}{l}\text { Nilai rata- } \\
\text { rata }\end{array}$ & 1 & 0,33 & 0,33 \\
\hline $\begin{array}{l}\text { Hasil } \\
\text { psikotes }\end{array}$ & 3 & 1 & 1 \\
\hline $\begin{array}{l}\text { Hasil kuis } \\
\text { peminatan }\end{array}$ & 2 & 0,5 & 0,5 \\
\hline Jumlah & 6 & 1,83 & 1,83 \\
\hline
\end{tabular}

Angka 1 pada kolom nilai rata-rata baris nilai rata-rata menggambarkan tingkat kepentingan yang sama antara nilai rata-rata dengan nilai rata-rata, sedangkan angka 3 pada kolom nilai rata-rata baris hasil psikotes menunjukan hasil psikotes sedikit lebih penting dibandingkan nilai rata-rata. Angka 0.33 pada kolom hasil psikotes baris nilai rata-rata merupakan hasil perhitungan 1/nilai pada kolom nilai rata-rata baris karya tulis yaitu 3 . Angka-angka yang lain diperoleh dengan cara yang sama.

\section{Membuat Matriks Nilai Kriteria}

Matriks ini diperoleh dengan rumus berikut:Nilai baris kolom baru = Nilai bariskolom lama/jumlah masing-masing kolom lama Perhitungan untuk menentukan nilai barunya dapat dilihat pada tabel 3.2.

Tabel 3.2 Perhitungan Nilai Baru

\begin{tabular}{|l|c|c|}
\hline Deskripsi matriks & Range & Hasil \\
\hline $\begin{array}{l}\text { Kolom nilai rata-rata } \\
\text { baris nilai rata-rata }\end{array}$ & $1 / 6$ & 0,16 \\
\hline $\begin{array}{l}\text { Kolom nilai rata-rata } \\
\text { baris hasil psikotes }\end{array}$ & $3 / 6$ & 0,5 \\
\hline $\begin{array}{l}\text { Kolom nilai rata-rata } \\
\text { baris hasil peminatan }\end{array}$ & $2 / 6$ & 0,33 \\
\hline $\begin{array}{l}\text { Kolom hasil psikotes } \\
\text { baris nilai rata-rata }\end{array}$ & $0,33 / 1,83$ & 0,18 \\
\hline $\begin{array}{l}\text { Kolom hasil psikotes } \\
\text { baris hasil psikotes }\end{array}$ & $1 / 1,83$ & 0,54 \\
\hline
\end{tabular}

\begin{tabular}{|l|c|c|}
\hline $\begin{array}{l}\text { Kolom hasil psikotes } \\
\text { baris hasil peminatan }\end{array}$ & $0,5 / 1,83$ & 0,27 \\
\hline $\begin{array}{l}\text { Kolom hasil } \\
\text { peminatan baris nilai } \\
\text { rata-rata }\end{array}$ & $0,33 / 1,83$ & 0,18 \\
\hline $\begin{array}{l}\text { Kolom hasil } \\
\text { peminatan baris } \\
\text { hasil psikotes }\end{array}$ & $1 / 1,83$ & 0,54 \\
\hline $\begin{array}{l}\text { Kolom hasil } \\
\text { peminatan baris }\end{array}$ & $0,5 / 1,83$ & 0,27 \\
\hline
\end{tabular}

Hasil perhitungan dalam bentuk matriks bisa dilihat dalam tabel 3.3

Tabel 3.3 Matriks Nilai Kriteria

\begin{tabular}{|l|c|c|c|c|c|}
\hline & $\begin{array}{c}\text { Nilai } \\
\text { rata- } \\
\text { rata }\end{array}$ & $\begin{array}{c}\text { Hasil } \\
\text { psikot } \\
\text { es }\end{array}$ & $\begin{array}{c}\text { Hasi } \\
\text { kuis } \\
\text { peminat } \\
\text { an }\end{array}$ & $\begin{array}{c}\text { Ju } \\
\text { mla } \\
\text { h }\end{array}$ & $\begin{array}{c}\text { Pri } \\
\text { ori } \\
\text { tas }\end{array}$ \\
\hline $\begin{array}{l}\text { Nilai } \\
\text { rata- } \\
\text { rata }\end{array}$ & 0,16 & 0,18 & 0,18 & 0,5 & 0,1 \\
\hline $\begin{array}{l}\text { Hasil } \\
\text { psikotes }\end{array}$ & 0,5 & 0,54 & 0,54 & 1,5 & 0,5 \\
8 & & & & \\
\hline $\begin{array}{l}\text { Hasi } \\
\text { kuis } \\
\text { peminat } \\
\text { an }\end{array}$ & 0,33 & 0,27 & 0,27 & 0,8 & 0,2 \\
7 & & & & & \\
\hline
\end{tabular}

Nilai kolom jumlah pada tabel 3.2 diperoleh dari penjumlahan pada setiap barisnya. Untuk penjumlahan tiap barisnya yaitu sebagai berikut

Jumlah baris nilai rata-rata $\quad=0,16+0,18+$ $0,18=0.52$

Jumlah baris hasil psikotes $\quad=0,5+0,54+$ $0,54=1,58$

Jumlah baris kuis peminatan $\quad=0,33+0,27+$ $0,27=0,87$

Nilai pada kolom prioritas diperoleh dari nilai pada kolom jumlah dibagi dengan jumlah kriteria, dalam hal ini ada 3. Perhitungan prioritasnya yaitu :

Prioritas nilai rata-rata $=0,52 / 3=0,17$

Prioritas hasil psikotes $=1,58 / 3=0,52$

Prioritas kuis peminatan $=0,87 / 3=0,29$

\section{Membuat Matriks Penjumlahan Setiap Baris}

Matriks ini dibuat dengan mengalikan matriks perbandingan berpasangan yaitu tabel 3.1 dengan nilai prioritas pada tabel 3.3, yaitu sebagai berikut: 


$$
\left[\begin{array}{ccc}
1 & 0,33 & 0,33 \\
3 & 1 & 1 \\
2 & 0,5 & 0,5
\end{array}\right]\left[\begin{array}{l}
0,17 \\
0,52 \\
0,29
\end{array}\right]
$$

Perhitungan perkalian matriksnya dapat dilihat pada tabel 3.4 .

Tabel 3.4 Perkalian Matriks

\begin{tabular}{|l|c|c|}
\hline \multicolumn{1}{|c|}{ Deskripsi Matriks } & Range & Hasil \\
\hline $\begin{array}{l}\text { Nilai baris nilai rata-rata } \\
\text { kolom nilai rata-rata }\end{array}$ & $1 \times 0,17$ & 0,17 \\
\hline $\begin{array}{l}\text { Nilai baris nilai rata-rata } \\
\text { kolom hasil psikotes }\end{array}$ & $\begin{array}{c}0,33 \times \\
0,52\end{array}$ & 0,17 \\
\hline $\begin{array}{l}\text { Nilai baris nilai rata-rata } \\
\text { kolom hasil kuis } \\
\text { peminatan }\end{array}$ & $0,33 \times$ & 0,09 \\
\hline $\begin{array}{l}\text { Nilai baris hasil psikotes } \\
\text { kolom nilai rata-rata }\end{array}$ & $3 \times 0,17$ & 0,51 \\
\hline $\begin{array}{l}\text { Nilai baris hasil psikotes } \\
\text { kolom hasil psikotes }\end{array}$ & $1 \times 0,52$ & 0,52 \\
\hline $\begin{array}{l}\text { Nilai baris hasil psikotes } \\
\text { kolom hasil kuis } \\
\text { peminatan }\end{array}$ & $1 \times 0,29$ & 0,29 \\
\hline $\begin{array}{l}\text { Nilai baris hasil kuis } \\
\text { peminatan kolom nilai } \\
\text { rata-rata }\end{array}$ & $2 \times 0,17$ & 0,34 \\
\hline $\begin{array}{l}\text { Nilai baris hasil kuis } \\
\text { peminatan kolom hasil } \\
\text { psikotes }\end{array}$ & $0,5 \times$ & 0,26 \\
\hline $\begin{array}{l}\text { Nilai baris hasil kuis } \\
\text { peminatan kolom kuis } \\
\text { peminatan }\end{array}$ & $0,5 \times$ & 0,14 \\
\hline $\begin{array}{l}\text { Kolom jumlah pada } \\
0,29\end{array}$ & $0 b e 13.5$ & $\mathrm{diperol}$ \\
\hline
\end{tabular}

Kolom jumlah pada tabel 3.5 diperoleh dengan menjumlahkan nilai pada masingmasing baris tabel tersebut.Hasil perhitungan disajikan dalam tabel 3.5.

Tabel 3.5 Matriks Penjumlahan Setiap Baris

\begin{tabular}{|l|c|c|c|c|}
\hline & $\begin{array}{c}\text { Nila } \\
\text { i } \\
\text { rata } \\
- \\
\text { rata }\end{array}$ & $\begin{array}{c}\text { Hasil } \\
\text { psikote } \\
\text { s }\end{array}$ & $\begin{array}{c}\text { Hasil } \\
\text { kuis } \\
\text { peminata } \\
\mathbf{n}\end{array}$ & $\begin{array}{c}\text { Jumla } \\
\text { h per } \\
\text { baris }\end{array}$ \\
\hline $\begin{array}{l}\text { Nilai } \\
\text { rata-rata }\end{array}$ & 0,17 & 0,51 & 0,34 & 1,02 \\
\hline $\begin{array}{l}\text { Hasil } \\
\text { psikotes }\end{array}$ & 0,17 & 0,52 & 0,26 & 1,95 \\
\hline $\begin{array}{l}\text { Hasil } \\
\text { kuis } \\
\text { peminata } \\
\text { n }\end{array}$ & 0,09 & 0,29 & 0,14 & 0,52 \\
\hline
\end{tabular}

\section{Perhitungan Rasio Konsistensi}

Perhitungan ini digunakan untuk memastikan bahwa nilai rasio konsistensi (CR)
$<=0.1$. jika ternyata nilai CR lebih besar dari 0.1 , maka matriks perbandingan berpasangan harus diperbaiki. Untuk menghitung rasio konsistensi, dibuat tabel seperti terlihat dalam tabel 3.6.

Tabel 3.6 Perhitungan Rasio Konsistensi

\begin{tabular}{|l|c|c|c|}
\hline & $\begin{array}{c}\text { Jumlah } \\
\text { per baris }\end{array}$ & Prioritas & Hasil \\
\hline $\begin{array}{l}\text { Nilai rata- } \\
\text { rata }\end{array}$ & 1,02 & 0,17 & 1,37 \\
\hline $\begin{array}{l}\text { Hasil } \\
\text { psikotes }\end{array}$ & 1,95 & 0,52 & 2,47 \\
\hline $\begin{array}{l}\text { Hasil kuis } \\
\text { peminatan }\end{array}$ & 0,52 & 0,29 & 0,81 \\
\hline
\end{tabular}

Kolom jumlah per-baris diperoleh dari kolom jumlah per baris pada tabel 3.5, sedangkan kolom prioritas diperoleh dari kolom prioritas pada tabel 3.3.hasil merupakan penjumlahan dari jumlah per baris ditambah prioritas. Dari tabel 3.6, diperoleh nilai-nilai sebagai berikut :

Jumlah (penjumlahan dari nilai-nilai hasil) : 4,65

$\mathrm{n}$ (jumlah kriteria) : 3

$\lambda$ maks (jumlah/n) $: 4,65 / 3=1.55$

$\mathrm{Cl}(\lambda$ maks $-\mathrm{n} / \mathrm{n}):(1.55-3) / 3=-0.48$

CR (CI / IR (lihat Tabel 2.3)) : - $0.48 / 0.90=-$ 0.53

Oleh karena $\mathrm{CR}<0.1$, maka rasio konsistensi dari perhitungan tersebut bisa diterima.

\section{Menghitung Hasil}

Prioritas hasil perhitungan berdasarkan langkah yang telah diuraikan di atas, kemudian direkapitulasi kedalam matriks hasil yang terlihat dalam tabel 3.7

Tabel 3.7 Matriks Hasil

\begin{tabular}{|c|c|c|c|}
\hline & $\begin{array}{c}\text { Nilai } \\
\text { rata-rata }\end{array}$ & $\begin{array}{c}\text { Hasil } \\
\text { psikotes }\end{array}$ & $\begin{array}{c}\text { Hasil kuis } \\
\text { peminatan }\end{array}$ \\
\hline Prioritas & 1,37 & 2,47 & 0,81 \\
\hline
\end{tabular}

Dari matriks yang sudah ada, maka dapat diambil acuan ketika akan memilih jurusan yang ada di SMAN 1 Majalengka. Berdasarkan data yang didapat dari Tata Usaha dan akademik kesiswaan SMAN 1 Majalengka.terdapat 508 siswa yang terdaftar untuk pemilihan jurusan, dan salah satunya dapat di ambil sebagai contoh pemilihan jurusan sebagai berikut:

1. Aditya kusuma dewi : 
Nilai rata-rata $=\frac{7,5}{3} \times 100=250$

Hasil psikotes $=\frac{40}{3,4} \times 100=1176,47$

Hasil kuis peminatan $=\frac{50}{3,4} \times 100=1470,58$

2. Aulia martha puspita :

Nilai rata-rata $=\frac{7,0}{3} \times 100=233,33$

Hasil psikotes $=\frac{50}{3,4} \times 100=1470,58$

Hasil kuis peminatan $=\frac{60}{3,4} \times 100=1764,70$

3. Crasella jenaida kurniawan mas'an :

Nilai rata-rata $=\frac{8,0}{3} \times 100=266,66$

Hasil psikotes $\quad=\frac{60}{3,4} \times 100=$

1764,70

Hasil kuis peminatan $=\frac{70}{3,4} \times 100=2058,82$

4. Dea hardila :

Nilai rata-rata $=\frac{8,0}{3} \times 100=266,66$

Hasil psikotes $=\frac{70}{3,4} \times 100=2058,82$

Hasil kuis peminatan $=\frac{80}{3,4} \times 100=2666,66$

Hasil perhitungan kemudian dituangkan dalam matriks nilai siswa yang dapat dilihat pada tabel 3.8

Tabel 3.8 Nilai Siswa

\begin{tabular}{|l|c|c|c|}
\hline & $\begin{array}{c}\text { Nilai } \\
\text { rata- } \\
\text { rata }\end{array}$ & $\begin{array}{c}\text { Hasil } \\
\text { psikotes }\end{array}$ & $\begin{array}{c}\text { Hasil kuis } \\
\text { peminatan }\end{array}$ \\
\hline $\begin{array}{l}\text { Aditya } \\
\text { kusuma } \\
\text { dewi }\end{array}$ & 250 & 1176,47 & 1470,58 \\
\hline $\begin{array}{l}\text { Aulia } \\
\text { martha } \\
\text { puspita }\end{array}$ & 233,33 & 1470,58 & 1764,70 \\
\hline $\begin{array}{l}\text { Crasella } \\
\text { jenaida } \\
\text { kurniawan } \\
\text { mas'an }\end{array}$ & 266,66 & 1764,70 & 2058,82 \\
\hline Dea hardila & 266,66 & 2058,82 & 2666,66 \\
\hline
\end{tabular}

Nilai akhir yang didapat setiap siswa dari setiap kriteria didapat dengan mengalikan nilai siswa dengan prioritasnya. Perhitungannya dapat dilihat pada tabel 3.9

Tabel 3.9 Perhitungan Nilai Siswa

\begin{tabular}{|l|c|c|}
\hline \multicolumn{1}{|c|}{ Deskripsi } & Range & Hasil \\
\hline Nilai rata-rata & $250 \times 1,37$ & 342,5 \\
Aditya kusuma & & \\
dewi & & \\
\hline Nilai rata-rata & $233,33 \times$ & 319,66 \\
Aulia martha & 1,37 & \\
puspita & & \\
\hline
\end{tabular}

\begin{tabular}{|l|c|c|}
\hline $\begin{array}{l}\text { Nilai rata-rata } \\
\text { Crasella jenaida } \\
\text { kurniawan } \\
\text { mas'an }\end{array}$ & $\begin{array}{c}266,66 \times \\
1,37\end{array}$ & 365,32 \\
\hline $\begin{array}{l}\text { Nilai rata-rata } \\
\text { Dea hardila }\end{array}$ & $266,66 \times$ & 365,32 \\
\hline $\begin{array}{l}\text { Nilai hasil } \\
\text { psikotes Aditya } \\
\text { kusuma dewi }\end{array}$ & $1176,47 \times$ & 2905,88 \\
\hline $\begin{array}{l}\text { Nilai hasil } \\
\text { psikotes Aulia } \\
\text { martha puspita }\end{array}$ & $1470,58 \times$ & 3632,33 \\
\hline $\begin{array}{l}\text { Nilai hasil } \\
\text { psikotes }\end{array}$ & 2,47 & \\
$\begin{array}{l}\text { Crasella jenaida } \\
\text { kurniawan } \\
\text { mas'an }\end{array}$ & 2,47 & 4358,80 \\
\hline $\begin{array}{l}\text { Nilai hasil } \\
\text { psikotes Dea } \\
\text { hardila }\end{array}$ & $2058,82 \times$ & 5085,28 \\
\hline $\begin{array}{l}\text { Nilai hasil kuis } \\
\text { peminatan } \\
\text { Aditya kusuma } \\
\text { dewi }\end{array}$ & $1470,58 \times$ & 1191,16 \\
\hline $\begin{array}{l}\text { Nilai hasil kuis } \\
\text { peminatan Aulia } \\
\text { martha puspita }\end{array}$ & 0,81 & \\
\hline $\begin{array}{l}\text { Nilai hasil kuis } \\
\text { peminatan }\end{array}$ & $2058,82 \times$ & 1667,64 \\
$\begin{array}{l}\text { Crasella jenaida } \\
\text { kurniawan } \\
\text { mas'an }\end{array}$ & 0,81 & \\
\hline $\begin{array}{l}\text { Nilai hasil kuis } \\
\text { peminatan Dea } \\
\text { hardila }\end{array}$ & $2666,66 \times$ & 2159,99 \\
\hline
\end{tabular}

Makahasil penilaian akhir setiap siswa setelah dimasukkan kedalam sistem dapat dilihat pada tabel 3.10.

Tabel 3.10 Hasil Akhir

\begin{tabular}{|c|c|c|c|c|}
\hline & $\begin{array}{l}\text { Nilai } \\
\text { rata- } \\
\text { rata }\end{array}$ & $\begin{array}{c}\text { Hasil } \\
\text { psikot } \\
\text { es }\end{array}$ & $\begin{array}{c}\text { Hasil } \\
\text { kuis } \\
\text { peminata } \\
\text { n }\end{array}$ & Total \\
\hline $\begin{array}{l}\text { Aditya } \\
\text { kusuma } \\
\text { dewi }\end{array}$ & 342,5 & $\begin{array}{c}2905,8 \\
8\end{array}$ & 1191,16 & $\begin{array}{c}4439, \\
54\end{array}$ \\
\hline $\begin{array}{l}\text { Aulia } \\
\text { martha } \\
\text { puspita }\end{array}$ & 319,66 & $\begin{array}{c}3632,3 \\
3\end{array}$ & 1429,40 & $\begin{array}{c}5381, \\
39\end{array}$ \\
\hline $\begin{array}{l}\text { Crasella } \\
\text { jenaida } \\
\text { kurniaw } \\
\text { an } \\
\text { mas'an }\end{array}$ & 365,32 & $\begin{array}{c}4358,8 \\
0\end{array}$ & 1667,64 & $\begin{array}{c}6391, \\
76\end{array}$ \\
\hline $\begin{array}{l}\text { Dea } \\
\text { hardila }\end{array}$ & 365,32 & $\begin{array}{c}5085,2 \\
8\end{array}$ & 2159,99 & $\begin{array}{c}7610, \\
59\end{array}$ \\
\hline
\end{tabular}


Kolom total pada Tabel 3.10 diperoleh dari penjumlahan pada masing-masing barisnya. Nilai total inilah yang dipakai sebagai dasar untuk menentukan jurusan siswa. Nilai yang paling besar ialah yang masukjurusan MIPA dan yang paling sedikit nilainya ialah yang masuk jurusan BAHASA dari beberapa persen nilai standar untuk masuk jurusan yang dipilih.

\section{KESIMPULAN}

Dari hasil uraian yang telah dijelaskan pada bab-bab sebelumnya, maka penulis dapat menarik kesimpulan sebagai berikut :

1. Sistem Pendukung Keputusan yang dibuat dengan menggunakan metode AHP sehingga dapat mengurangi masalah dalam pengambilan keputusan pemilihan jurusan SMA.

2. Sistem Pendukung Keputusan yang dibuat dengan menggunakan Analytic Hierarchy Process (AHP), sehingga diharapkan dapat membantu dalam pemilihan jurusan SMA.

3. Kriteria yang dibutuhkan dalam proses pemilihan jurusan SMA adalah menghitung nilai rata-rata, mengambil data hasil psikotes, mengikuti kuis peminatan.

\section{REFERENSI}

Dr.Azhar Susanto, MBUS, AK, 2004,dalam kutipan bukunya sistem informasi manajemen (konsep dan pengembangan) Bandung:lingga jaya 2004.

Okky cintya devi,2013, Jurnal sisten pendukung keputusan, Universitas Brawijaya 2013.

Indana julfa,2014, Jurnal sistem pendukung keputusan jurusan SMA menggunakan AHP, program study Informatika, program teknologi informasi dan ilmu komputer Universitas Brawijaya, 2014.

Thomas L.Ssaaty,1970,untuk artikel berjudul," Analitycal Hierarchy Process (AHP)",1970. 